\title{
Comprehensive Experimental Study on the Migration Law of the Floor at the Mining Face
}

\author{
Liquan Guo ${ }^{1,2 *}$, Zuopeng Jiang² \\ ${ }^{1}$ State Key Laboratory of Mining Response and Disaster Prevention and Control in Deep Coal Mines, Anhui University of Science \\ and Technology, Huainan, China \\ ${ }^{2}$ School of Earth and Environment, Anhui University of Science and Technology, Huainan, China \\ Email: *guoliquan78@126.com
}

How to cite this paper: Guo, L.Q. and Jiang, Z.P. (2020) Comprehensive Experimental Study on the Migration Law of the Floor at the Mining Face. Open Journal of Geology, 10, 981-990.

https://doi.org/10.4236/ojg.2020.1010045

Received: September 30, 2020

Accepted: October 26, 2020

Published: October 29, 2020

Copyright (c) 2020 by author(s) and Scientific Research Publishing Inc. This work is licensed under the Creative Commons Attribution International License (CC BY 4.0).

http://creativecommons.org/licenses/by/4.0/

\begin{abstract}
Under the circumstance that deep mining is increasingly vulnerable to underlying limestone water, accurate detection of floor failure depth ranges at a mining face becomes rather critical to coal mine production in safety. Underground borehole fiber optic sensing technology is combined with 2-D parallel electrical surveying to comprehensively monitor and analyze development laws of floor deformation and failure. Moreover, a working face 1022 in a mine of Huaibei Mining Area was taken, for example, introducing the layout of monitoring borehole and installation of relevant sensing units. Based on the stope progress of a working face, data related to strain and geoelectric fields were collected regularly to analyze relationships of field source variation characteristics and strata deformation failures. In this way, the development mechanism of the floor deformation failure can be revealed. As demonstrated by results, the depth failure of the floor at coal seam 10 is calculated to be $15 \mathrm{~m}$, while its disturbance depth turns out to be $22 \mathrm{~m}$. Due to advanced stress, concentrated stope load and post-mining pressure relief, the floor experienced elastic deformation, shear deformation and swelling deformation successively. Without a doubt, testing results obtained have scientific guiding significance for mines with similar geological conditions.
\end{abstract}

\section{Keywords}

Floor, Water Prevention and Control, Optical Fiber, Resistivity, Electric Current

\section{Introduction}

Deep mining in Northern and Eastern China is subjected to more threats from water disasters; and mining under pressure leads to frequent accidents caused by water disasters. It has been proved in corresponding literature that the depth of 
the floor failure is a key parameter for water disaster prevention and control of the floor of a working face [1] [2].

Now, research on the floor failure of a working face is concerned with fundamental theories, numerical simulation, physical modeling and field testing, etc. Among them, fundamental theories primarily include a water bursting coefficient method, and "down three zones" and "down four zones" of floor [3] [4] [5]. However, floor strata are mostly investigated from a macroscopic perspective. In terms of simulation tests suitable for shallow coal seams with a simple structure, they are inapplicable to deep strata complicatedly structured [6]. As for field testing, geophysical prospecting plays a significant role, such as seismic exploration, a high-density resistivity method, 3-D parallel electrical surveying and an electromagnetic method [7] [8] [9]. In most cases, field exploration is completed based on a single physical property and it is also less likely for their detection accuracy to meet the requirements of precision exploration. Therefore, the multi-physics testing technology has also conducted a lot of research on the deformation and failure of the surrounding rock [10] [11].

As the working face keeps advancing, its floor may undergo three phases of compression caused by advanced stress, swelling caused by floor pressure relief due to post-mining roof suspension, and re-compaction caused by roof caving later. In this period, both the mining effect and external additional stress make stress state in the floor out-of-balance, generating deformation failures to diverse degrees and forming a floor failure zone with a certain depth. Considering this, it is of important theoretical meaning for investigations on mine pressure-related theories to accurately, comprehensively and quantitatively master deformation distribution and evolving characteristics of the floor strata [12] [13].

In this paper, Brillouin optical time domain reflectometry (BOTDR) [14] is mainly used, together with 2-D parallel electrical surveying [15], to comprehensively test the laws of the floor deformation failure in a stope. By testing strain and geoelectric fields of a floor during coal seam mining, lithologic combination features are also taken into consideration to analyze floor deformation failure laws. Hence, depths of the floor failure zone and the disturbance failure zone are acquired. Clearly, the obtained research results play an essential part in constructing multi-field tests for floor deformation failures in a stope.

\section{Overview of the Working Face}

The selected research region is the working face 1022 in a mine of Huaibei Mining Area, the specific location of the case study area is shown in Figure 1; and its major working seam is the coal seam 10. To be specific, elevations of the working face and the coal seam floor are proved to be $-429 \mathrm{~m}--345 \mathrm{~m}$ and about $-425 \mathrm{~m}$, respectively. The geological structure of this working face is relatively simple, with little change in coal seam occurrence, and is a monoclinic structure. Small faults in the working face are relatively developed. During the mining process, 16 faults above $1.0 \mathrm{~m}$ are actually exposed, of which 7 
are exposed in haulage roadway and 9 are exposed in ventilation roadway, all of which are normal faults with a maximum drop of $4.5 \mathrm{~m}$. Moreover, the dip of coal seam 10 ranges from $14^{\circ}$ to $20^{\circ}\left(17^{\circ}\right.$ on average). As for the lithologic characters of the floor and the roof of this working face, they have been listed in Table 1. Within the range of stoping, the average working thickness of the coal seam is about $3.2 \mathrm{~m}$. Also, stoping was fulfilled through fully mechanized top-coal caving.

\section{Monitoring Coefficient Construction}

\subsection{Borehole Monitoring Parameters}

According to specific tasks and construction conditions for investigations on the law of floor failure at a working face, a borehole monitoring system for floor failures was arranged in haulage and ventilation roadways respectively at the working face 1022. Within the borehole, sensing optical cables and electrodes were all mounted. The borehole was situated at the haulage roadway, forming an azimuth of $118^{\circ}$, an included angle of $20^{\circ}$ with the roadway, an angle of depression

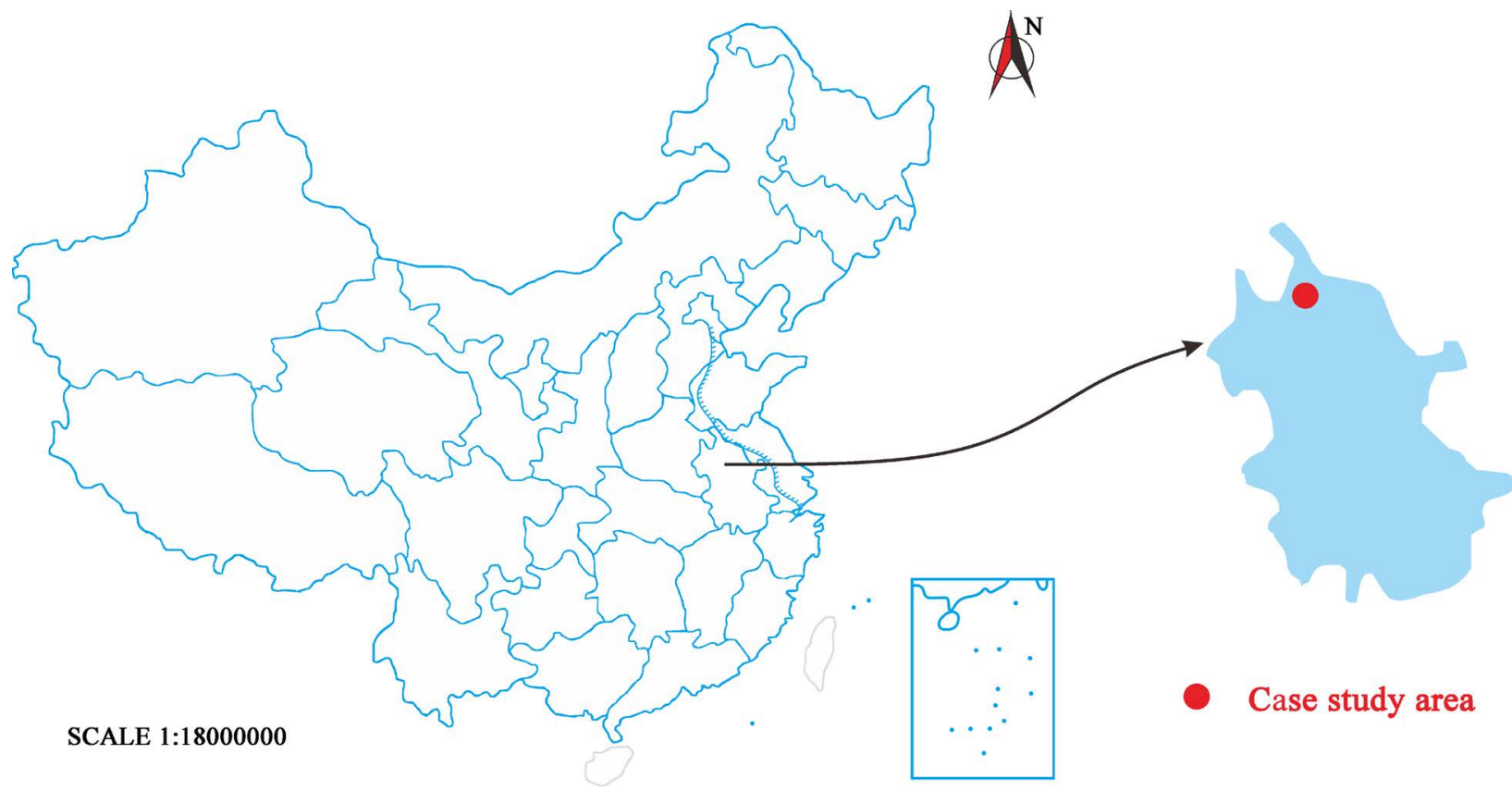

Figure 1. The map of the case study area.

Table 1. Lithologic characters of the floor and the roof of working face 1022.

\begin{tabular}{cccc}
\hline Floor or roof & Rock & Thickness (m) & Lithologic character \\
\hline Upper roof & Fine sandstone & 9.25 & Grey or dark grey; mainly feldspar and quartz; compact \\
Immediate roof & Mudstone & 2.33 & Dark grey; slightly silty; with abundant plant fossils \\
Immediate floor & Coal seam 10 & 3.2 & Black; fragmental; showing glassy luster; mainly dull and bright coal \\
Hard floor & Fine sandstone & 2.00 & Dark grey ash black; in bulks; containing fragments of plant fossils \\
\hline
\end{tabular}


of $30^{\circ}$, a depth of $75 \mathrm{~m}$, a control vertical height of $37.5 \mathrm{~m}$ and a control horizontal distance of $61 \mathrm{~m}$ from the working face. As for the layout of borehole, it is presented in Figure 2.

\subsection{Sensing Unit Installation}

To meet the requirements of large deformation monitoring for the mine, sensing optical cables and electrodes were all made of processing materials for special purposes. After the borehole have been put in place, a polyvinyl chloride (PVC) pipeline was utilized to implant cables and electrodes into them; next, the borehole was sealed and underwent full grouting, making sure that cables and electrodes could be sufficiently coupled to surrounding rocks. Since sensing units in the borehole have been mounted, the cables and electrodes were led up along a roadway sidetrack to the main roadway and connected with a BOTDR instrument and a parallel electrical surveying apparatus, making preparations for subsequent data acquisition.

\subsection{Data Acquisition}

Since borehole installation has been completed, initial values of relevant data were collected. Data associated with optical cables and electrodes in the borehole was collected from January 17 to May 4, 2018, producing 35 sets of optical cable and electrical surveying data. Then, the retreat site of the stope face was $157 \mathrm{~m}$ away from the monitoring section when the data were collected for the first time. Moreover, the data firstly collected were used as initial values. As the working face continuously advanced, monitoring frequency was elevated gradually. Once the monitoring section is rather close to the monitoring area, data acquisition was reinforced on one hand; and on the other hand, variations in strain distribution, stress distribution and resistivity of the floor were monitored dynamically. For this reason, real-time whole-process monitoring was achieved,

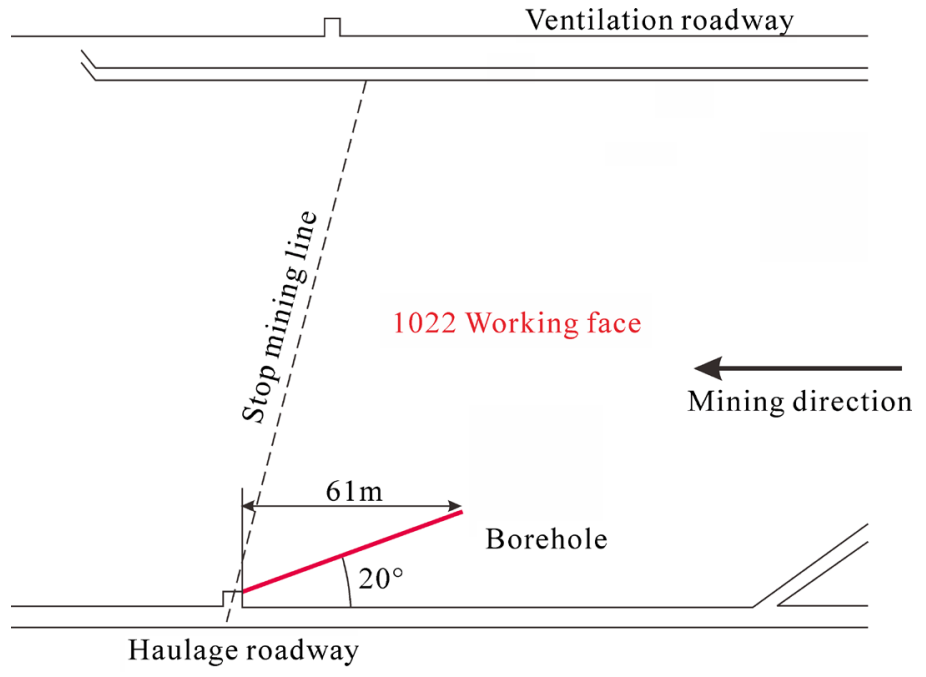

(a)

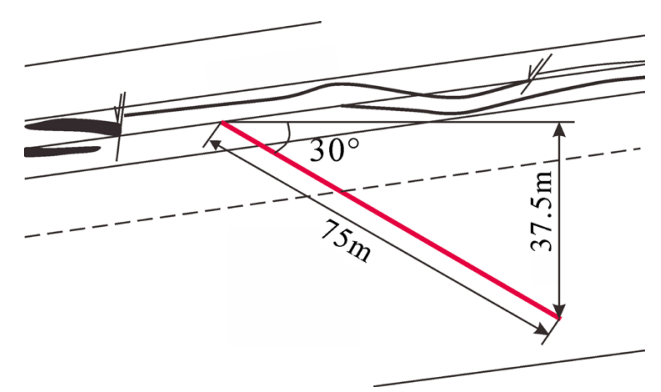

(b)

Figure 2. Layout diagram of the section. (a) The layout plan of borehole; (b) The profile of borehole. 
generating not only background data of the floor free of the influence from working face stoping, but also variation rules of strain and stress fields when the floor is inclined to be steady in processes where the floor begins to deform, floor deformation takes form and the working face advances and reaches goaf.

\section{Monitoring Data Analysis}

\subsection{Strain Distribution and Variation Features}

The borehole has an angle of depression of $30^{\circ}$. As for the length of installed cables, the control horizontal distance and the control vertical depth, they are designed at $75 \mathrm{~m}, 61 \mathrm{~m}$ and $37.5 \mathrm{~m}$, respectively.

Strain distribution curves of sensing optical cables in borehole are shown in Figure 3. Here, tensile strain is defined to be positive, while compressive strain negative (the same below). As can be observed from Figure 3, optical cables mainly suffer from compressive strain when the working face is rather far from the monitoring opening. This indicates that the floor is compressed on the whole before it is subjected to an impact of advanced mining stress. As the working face advances and becomes rather close to the monitoring opening, coal seams in upper layers of the rock strata under the control of the corresponding borehole can be mined. Due to pressure relief caused by the suspension of the upper strata, vertical shear forces were generated, leading to a slight tensile strain. The maximum compressive strain of the borehole is $-2500 \mu \varepsilon$, produced at a place $33 \mathrm{~m}$ deep. In this case, the working face is $30 \mathrm{~m}$ away from the monitoring opening (March 26). Regarding the maximum tensile strain, it turns out to be $714 \mu \varepsilon$, formed in a place $7.4 \mathrm{~m}$ deep in the borehole. Under this circumstance, the distance from the working face to the monitoring opening is $19 \mathrm{~m}$ (April 3).

To better analyze spatio-temporal relationships of strain distribution in optical

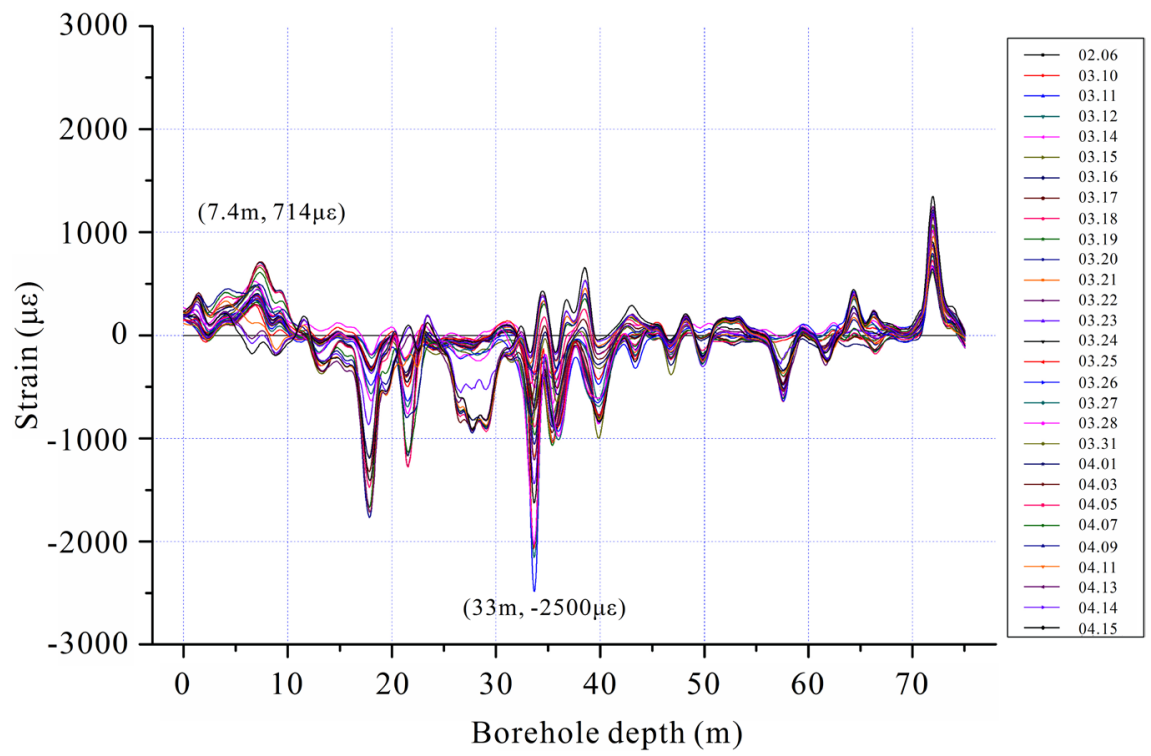

Figure 3. Strain distribution of optical cables in borehole. 
cables and the rock strata, a spatio-temporal variation cloud atlas was portrayed for strains within the control range of borehole (see Figure 4). In Figure 4, the $\mathrm{x}$-axis refers to the date of monitoring and corresponding advance footage of the working face on that very day; and the y-axis represents valid vertical depth under the control of the borehole. As for diurnal variations, they are denoted by differences between a strain of the optical cable monitored in a later phase and the collected background value.

Through analysis in Figure 4, it is clear that, within a range of $52.7 \mathrm{~m}$ under horizontal control of the borehole, compressive strain appears at a sandy mudstone and sandstone interface $20 \mathrm{~m}$ below the floor when the working face is 65 $\mathrm{m}$ away from the monitoring section on March 14. Provided that the working face keeps advancing, nevertheless, strain values at this interface elastically change; in other words, the compressive strain rebounds. Besides, a mudstone-seam interface $4 \mathrm{~m}$ below the floor begins to suffer slight tensile strains. Likewise, tensile strain values also rebound in the context where the working face constantly advances. This signifies that the above two interfaces are merely subjected to advanced stress, but no brittle failures occur. Therefore, only disturbance influence of the floor takes form. Furthermore, when the working face becomes $27.5 \mathrm{~m}$ away from the monitoring section on March 28, obvious compressive strain variations can be observed at a sandstone-sand-mudstone interface $10 \mathrm{~m}$ below the floor and a sand-mudstone layer $15 \mathrm{~m}$ below the floor. Within the valid period of monitoring, a compressive strain is always present in this formation. According to the analysis in combination with strain values presented in Figure 2, no rebound strain is produced in the corresponding formation that suffers a plastic failure.

By means of comprehensive analysis, floor failure depth is about $15 \mathrm{~m}$ within a valid range of a formation under the control of the borehole; and it occurs in the upper segment of sandy mudstone in the lower part of coal seam 10. Corresponding disturbance influence reaches $20 \mathrm{~m}$ roughly to the upper part of the sandstone formation below the coal seam 10 .

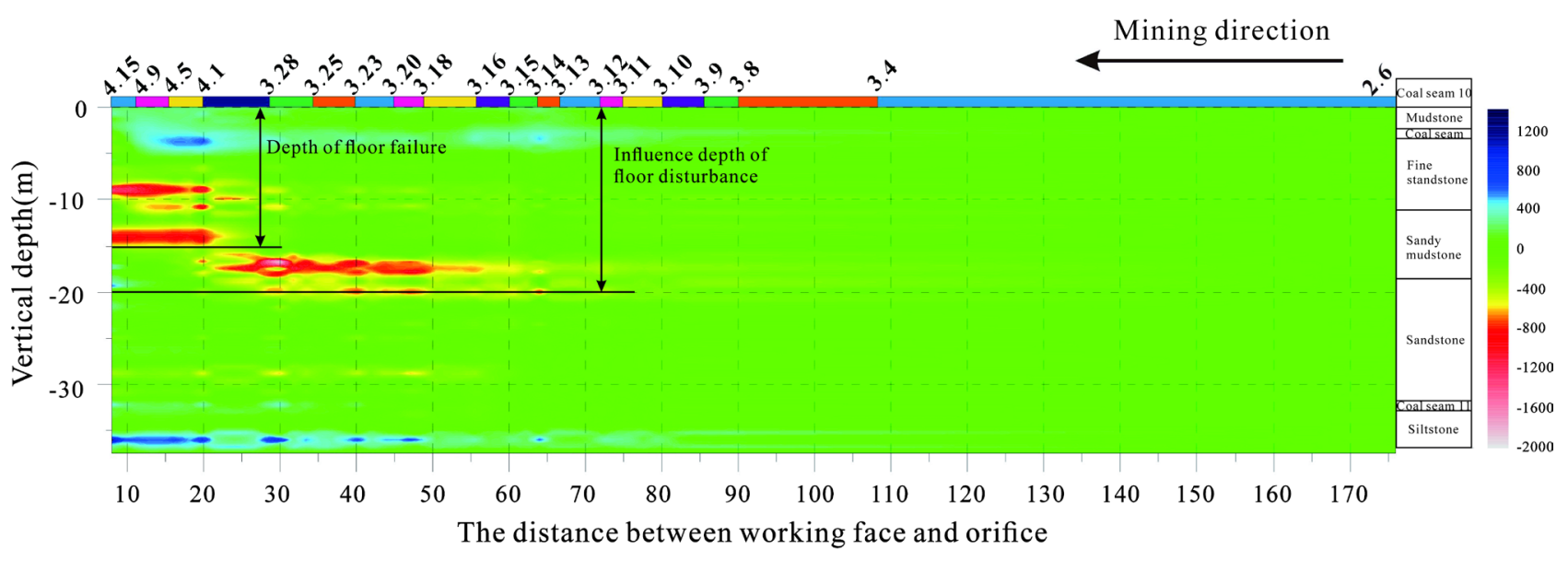

Figure 4. A schematic diagram of spatio-temporal strain variations within the control range of borehole. 


\subsection{Geoelectric Field Distribution and Variation Features}

Figure 5 presents a distribution diagram of spatio-temporal variations of electric currents within the control range of borehole in the haulage roadway. In this figure, while the $\mathrm{x}$-axis represents the date of monitoring and working face advance footage on that very day, the $y$-axis is the valid vertical depth under the control of borehole. Moreover, diurnal variation data here refer to electric current values each day. According to the cloud atlas of electric currents incurred by borehole in Figure 5, no significant variations are found in electric current values at an early stage of monitoring on one hand; and on the other hand, their basic background values are also similar to each other. A reason is that the open-off cut of the working face is rather distant from the monitoring opening in the early phases of monitoring, so that mining-induced advanced stress places an insignificant influence on the monitoring opening. In the context where the open-off cut described above is $64 \mathrm{~m}$ away from the monitoring opening (March $14)$, electric current values begin to change dramatically at an interface $(5 \sim 8 \mathrm{~m}$ below the floor) between the sandy mudstone formation and the upper sandstone. In this case, the electric current values decline, but the corresponding resistivity rises. A reason why the above-mentioned phenomena take place is that the open-off cut of the working face is located within the horizontal control range of borehole and also rather close to the monitoring opening. Consequently, the advanced stress has the potential to significantly affect an interface between the sandstone formation and the sandy mudstone formation, further leading to formation fracturing, resistivity increase and current value drop. As for the sandstone formation $22 \mathrm{~m}$ below the floor, its electric current values also decline slightly. This indicates that such a formation is subjected to a minor influence from the advanced stress. Once the open-off cut is $49 \mathrm{~m}$ away from the monitoring opening (March 18), an apparent variation is observed at the sandy mudstone formation as well as its interface with the lower sandstone $(10 \sim 16 \mathrm{~m}$ below the floor). Such a phenomenon is manifested in a decline of electric current values but a rise of resistivity. Corresponding reasons are elaborated as

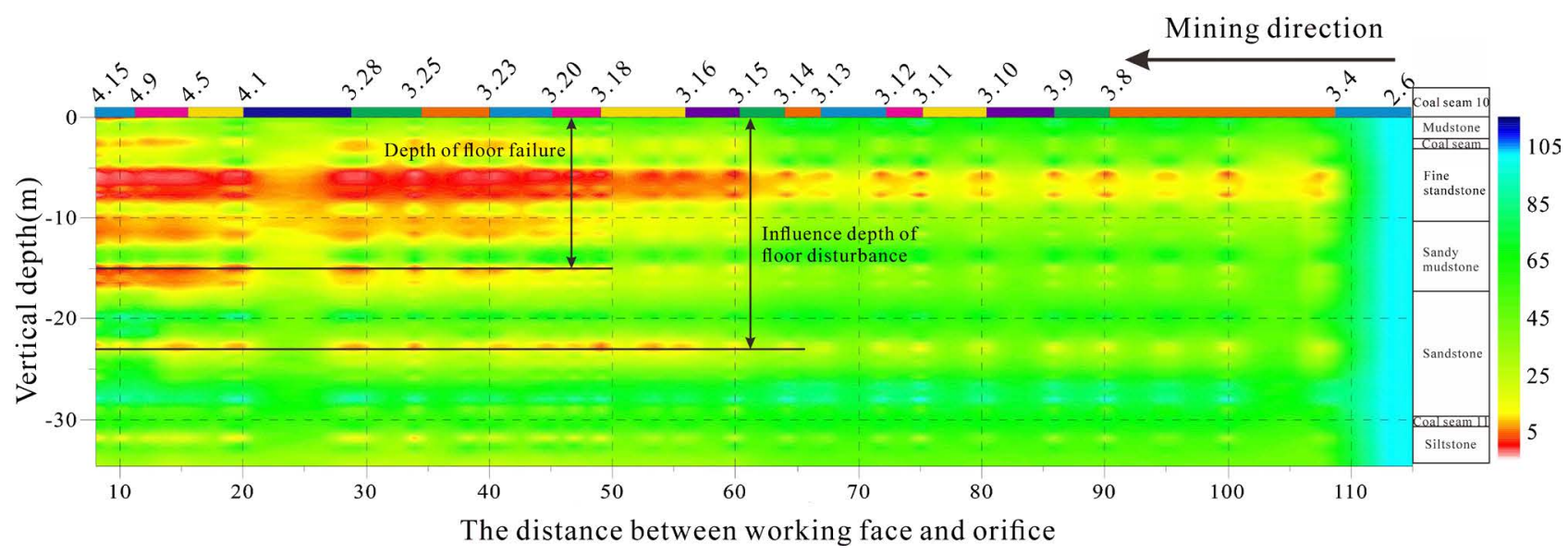

Figure 5. A cloud atlas of electric current distribution during monitoring. 
follows: the open-off cut mentioned above becomes closer to the monitoring opening, exerts more influence on soft rock strata, causing fractures or size reduction in the strata, and enabling the corresponding resistivity to go up. Based on the cloud atlas, electric current values during data collection always remain steady at the sandy mudstone formation and its interface with the upper fine sandstone or the lower sandstone. Through comprehensive analysis, it can be known that failure depth and disturbance influence depth of the floor strata are proved to be $15 \mathrm{~m}$ and $22 \mathrm{~m}$, respectively.

\subsection{Comprehensive Analysis}

Sensing optical cables related data and results obtained by parallel electric surveying are comprehensively analyzed. It is proved by such analytical results that exploration outcomes of such two approaches are basically consistent with each other. Thanks to mutual validation between the two observation systems, exploration outcomes achieved can be more persuasive and scientific.

According to a comprehensive analysis of data associated with sensing optical cables in borehole of haulage, it can be summarized as follows: failure depth and disturbance influence depth of the floor at coal seam 10 are calculated to be $15 \mathrm{~m}$ and $20 \mathrm{~m}$ respectively. During the mining of the working face, mining-induced deformations are incurred on the floor because of advanced stress, mining-induced concentrated load and post-mining pressure relief. Successively, the floor experiences elastic deformation, shear deformation and swelling deformation.

With regard to borehole in haulage roadway, relevant data obtained by the electric surveying method are also comprehensively analyzed. It turns out that the floor failure depth of coal seam 10 is also $15 \mathrm{~m}$. In this range, its resistivity reaches $800 \Omega \cdot m$ and above. As for overlying strata suffering insignificant mining-induced influence, their resistivity values are generally below $250 \Omega \cdot \mathrm{m}$. Clearly, the resistivity may go up to another value several times greater. Furthermore, resistivity variation features and electric current values are comprehensively analyzed as well. It is shown by analytical results that floor failure depth is $15 \mathrm{~m}$ at the sandy mudstone segment of the floor. Resistivity values within this range have a typical characteristic, that is, the floor failure is charged. In terms of its disturbance influence depth, it is proved to be $22 \mathrm{~m}$.

As comprehensively analyzed, failure depth and disturbance influence depth of the floor are $15 \mathrm{~m}$ and $22 \mathrm{~m}$ respectively during mining of the coal seam 10 , as shown in Table 2.

Table 2. Comprehensive testing results for mining-induced floor deformation failures of the working face 1022 .

\begin{tabular}{cccc}
\hline & Optical fiber & Electrical method & Comprehensive analysis \\
\cline { 2 - 4 } Depth of floor failure $(\mathrm{m})$ & 15 & 15 & 15 \\
Disturbance influence depth $(\mathrm{m})$ & 20 & 22 & 22 \\
\hline
\end{tabular}




\section{Discussion}

In this paper, optical fiber testing technology and resistivity technology are used to effectively test the deformation and failure of the floor, but there are still shortcomings, which can be further studied in the future:

1) Monitoring of multiple sections using the same test technology in different areas of the same working face, the data obtained is more scientific.

2) It is necessary to further develop the plugging material in the borehole to ensure the enhanced coupling of the borehole.

\section{Conclusions}

In this study, optical cables in borehole are combined with electric surveying to comprehensively monitor floor deformation failures during mining of the coal seam 10. At last, the conclusions can be drawn below.

1) Targeted at floor strata, strain distribution features and resistivity and electric current distribution laws of sensing optical cables are comprehensively analyzed. According to relevant analytical results, it is found that mining-induced failure depth of the floor is $15 \mathrm{~m}$ for the coal seam 10 and its disturbance influence depth is $22 \mathrm{~m}$.

2) With regards to strains and electric currents, etc. of sensing optical cables in the borehole, they are distributed in a segmental way. For example, rock strata with a comparatively high elastic modulus are featured with a slight strain variation, low resistivity and high electric current values; or vice versa.

3) Floor deformation failure is under the influence of multiple factors. To be specific, parameters such as mining height, mining thickness and formation lithology play a major role in the development of floor failure depth. In this consideration, relationships of floor failure and diverse parameters need to be more profoundly investigated in subsequent research. Hopefully, technical support can be provided for safe, high-efficiency and green coal mining.

To sum up, the proposed integrated monitoring technique combining distributed optical cables with 2-D parallel electric surveying has the capability to realize dynamic whole-process monitoring on floor deformation failures during coal mining. As the achieved results can be validated mutually, the multiplicity of solutions to inversion outcomes can be lowered to some degree. In this way, corresponding interpretation accuracy is improved. Without a doubt, a new research method is thus provided for investigations on mining-induced surrounding rock deformation failures in later stages.

\section{Acknowledgements}

The authors gratefully acknowledge the staff of the Geotechnical Survey Department of Jiegou Coal Mine for their strong support during the on-site monitoring.

\section{Conflicts of Interest}

The authors declare no conflicts of interest regarding the publication of this paper. 


\section{References}

[1] Bai, X.Q., Bai, H.B. and Shen, Z.H. (2009) Relative Strata Impermeability in Ordovician Top and Risk Assessment of Water Inrush from Coal Floor in Xinyi Coalfield. Chinese Journal of Rock Mechanics and Engineering, 28, 273-280.

[2] Sun, Y.J., Zuo, J.P., Karakus, M., et al. (2019) Investigation of Movement and Damage of Integral Overburden during Shallow Coal Seam Mining. International Journal of Rock Mechanics and Mining Sciences, 117, 63-75.

https://doi.org/10.1016/j.ijrmms.2019.03.019

[3] Shi, L.Q. (2009) Summary of Research on Mechanism of Water-Inrush from Seam Floor. Journal of Shandong University of Science and Technology (Natural Science), 29, 17-22.

[4] Jing, Z.G. and Li, B.Y. (1980) Preliminary Study about Water-Inrush from Floor. Coal Field Geology and Exploration, 27-29.

[5] Shi, L.Q., and Han, J. (2005) Theory and Practice of Dividing Coal Mining Area Floor into Four-Zone. Journal of China University of Mining \& Technology, 34, 16-23.

[6] Cheng, J.L. and Yu, S.J. (2000) Simulation Experiment on the Response of Resistivity to Deformation and Failure of Overburden. Chinese Journal of Geophysics, 43, 740-748. https://doi.org/10.1002/cjg2.89

[7] Zhang, P.S., Wu, J.W. and Liu, S.D. (2006) Study on Dynamic Observation of Coal Seam Floor's Failure Law. Chinese Journal of Rock Mechanics and Engineering, 25, 3009-3013.

[8] Wu, R.X., Zhang, P.S. and Liu, S.D. (2009) Exploration of Two-Gateway Network Parallel Electrical Technology for Exploring Thin-Coal Area within Coal Face. Chinese Journal of Rock Mechanics and Engineering, 28, 1834-1838.

[9] Yang, F. and Peng, S.-P. (2006) New Method of Ground Penetrating Rader (GPR) Exploration to Near Hidden Trouble under Mining. Journal of China Coal Society, 31, 1-4.

[10] Sun, B.Y., Zhang, P.S., Wu, R.X., et al. (2020) Improvement of Upper Limit of Mining under an Aquifer of a Super Thick Unconsolidated Layer in Huainan Based on Multi Physics Field Monitoring. Exploration Geophysics. https://doi.org/10.1080/08123985.2020.1780116

[11] Sun, B.Y., Zhang, P.S., Wu, R.X., et al. (2018) Dynamic Detection and Analysis of Overburden Deformation and Failure in a Mining Face Using Distributed Optical Fiber Sensing. Journal of Geophysics and Engineering, 15, 2545-2555. https://doi.org/10.1088/1742-2140/aad1c6

[12] Qian, M.G., Miao, X.X. and Xu, J.L. (1996) Theoretical Study of Key Stratum in Ground Control. Journal of China Coal Society, 21, 44-47.

[13] Zhang, J.C. and Liu, T.Q. (1990) Research on the Depth and Distribution of Coal Mining Floor. Journal of China Coal Society, 15, 35-38.

[14] Zhang, P.S. and Sun, B.Y. (2020) Distribution Characteristics of the Advance Abutment Pressure in a Deep Stope. Journal of Geophysics and Engineering, 17, 686-699. https://doi.org/10.1093/jge/gxaa022

[15] Zhang, P.S., Liu, S.D. and Wu, R.X. (2009) Dynamic Detection of Overburden Deformation and Failure in Mining Workface by 3D Resistivity Method. Chinese Journal of Rock Mechanics and Engineering, 28, 1870-1875. 